\title{
Antimetastatic activities of heparins and modified heparins. Experimental evidence
}

\author{
Borsig, L
}

\begin{abstract}
Heparin is commonly used for prevention or treatment of cancer-associated thromboembolism. Recent clinical evidence indicates that heparin, and low-molecular weight heparin improves survival of cancer patients. Experimental evidence from various animal models consistently supports the ability of heparin to attenuate metastasis. Heparin, apart from its anticoagulant activity contains a variety of biological activities possibly affecting cancer progression, including: inhibition of heparanase, blocking of $\mathrm{P}$ - and L-selectin mediated cell adhesion, and inhibition of angiogenesis. The delineation of antimetastatic activity of heparin is in the focus of several ongoing investigations. This review summarizes the current experimental evidence on the biology of heparin as a potential treatment cancer progression.
\end{abstract}

DOI: https://doi.org/10.1016/S0049-3848(10)70017-7

Posted at the Zurich Open Repository and Archive, University of Zurich

ZORA URL: https://doi.org/10.5167/uzh-40788

Journal Article

Accepted Version

Originally published at:

Borsig, L (2010). Antimetastatic activities of heparins and modified heparins. Experimental evidence. Thrombosis Research, 125(Suppl2):S66-S71.

DOI: https://doi.org/10.1016/S0049-3848(10)70017-7 
Manuscript

Antimetastatic activities of heparins and modified heparins. Experimental evidence.

\author{
Lubor Borsig \\ Institute of Physiology, University of Zürich and Zürich Center for Integrative Human \\ Physiology, Zürich, Switzerland
}

Corresponding author: Lubor Borsig

Institute of Physiology

University of Zürich

Winterthurerstrasse 190

CH-8057 Zürich

Switzerland

Tel: +41 446355134

Fax: +41 446356814

Email: 1borsig@access.uzh.ch

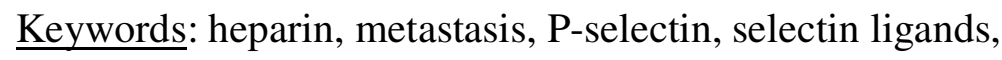

Word count: 2839 


\begin{abstract}
Heparin is commonly used for prevention or treatment of cancer-associated thromboembolism. Recent clinical evidence indicates that heparin, and low-molecular weight heparin improves survival of cancer patients. Experimental evidence from various animal models consistently supports the ability of heparin to attenuate metastasis. Heparin, apart from its anticoagulant activity contains a variety of biological activities possibly affecting cancer progression, including: inhibition of heparanase, blocking of $\mathrm{P}$ - and L-selectin mediated cell adhesion, and inhibition of angiogenesis. The delineation of antimetastatic activity of heparin is in the focus of several ongoing investigations. This review summarizes the current experimental evidence on the biology of heparin as a potential treatment cancer progression.
\end{abstract}




\section{Introduction}

Cancer-associated thrombosis is a frequent complication associated with cancer progression [1]. Heparin and low molecular weight heparin (LMWH) are commonly used for the prevention or treatment of thromboembolic complications in cancer patients [2, 3]. Based on earlier observations linking the anticoagulant therapy with heparin to an improved survival of cancer patients, several prospective clinical trial were launched with the aim to test heparin as a potential anticancer treatment (see reviews [4-6]. Preclinical analysis of heparin provides evidence for its antimetastatic activity in a variety of animal models (see reviews [7, 8]. While the potential of heparin to attenuate metastasis in experimental models is well accepted, the underlying molecular mechanism of heparin action in this process is a topic of ongoing investigations.

Heparin is a complex mixture of natural glycosaminoglycans purified from porcine intestine [9]. These linear polymers are composed of a repetitive disaccharide unit containing a glucosamine residue and glucuronic/iduronic acid [10]. Both units are sulfated and the degree of sulfation of the disaccharide units varies throughout the polymer. Clinical preparation of heparin is a polydisperse mixture of glycosaminoglycans that is adjusted for the anticoagulant activity [9]. However, only a small portion of the heparin preparation actually contains the anticoagulant activity. The binding site of heparin to antithrombin III has been identified as a specifically sulfated pentasaccharide sequence [9]. In addition, multiple subsets of heparin chains were shown to interact with a large number of other molecules including enzymes (e.g. heparanase), cell adhesion molecules (e.g. P- and L-selectin), growth factors and cytokines [9, 11-13]. Specific targeting of any of these biological activities by heparin or LMWH was shown to affect the biology of cancer in certain models. Nevertheless, an identification of the critical biological activity of heparin responsible for the attenuation of metastasis was proven difficult due to the very nature of heparin that is represented by a mixture of 
glycosaminoglycans carrying partially overlapping biologically active sites. Nevertheless, the recent use of modified heparins with a characterized "narrower" biological activity in vivo points toward the critical role of heparin during metastasis [14-19].

\section{Heparin attenuates metastasis in animal models}

Heparin and LMWH were tested in many different animal models for their potential cancer inhibiting activity. Heparins were repeatedly shown to effect cancer progression, while their effect on tumor growth was rather limited $[16,20,21]$. Over the last twenty years, the antimetastatic activity of heparins was primarily observed in animal models of experimental metastasis (Table 1). An overview of studies prior to this period is excellently reviewed elsewhere [7, 8]. The experimental metastasis model does not completely recapitulate the natural process of metastatic spread, thus very early steps of local tumor cell dissemination and intravasation needs to be analyzed in spontaneous metastasis models. Despite many limitations of this experimental approach, the timely defined presence of tumor cells in circulation allows the evaluation of cellular and molecular mechanisms during the hematogenous phase of metastasis. Accordingly the biological effect of heparin during this process can be assessed. A variety of heparin preparations, including unfractionated heparin, LMW heparin and several chemically modified heparins with a reduced or a minimal anticoagulant activity, efficiently reduced metastasis when applied shortly before or after the tail vein injection of tumor cells (Table 1). When heparin was applied twenty four hours before or after the tumor cell injection no effect was observed [22, 23]. Only in one study heparin treatment one day before the tumor cell injection and daily during the first three days form tumor cell injection was reported to attenuate metastasis [24]. However, the attenuation of metastasis in this study may be affected largely by the heparin application at the time of tumor cell injection that was not specified [24]. In general, attenuation of metastasis was 
independent of the route of heparin application. Intravenous application of heparin around the time of tumor cell injection always led to reduction of metastasis. Subcutaneous or intraperitoneal application of heparin around the time of tumor cell injection led mostly to attenuation of metastasis $[11,14,20,25-27]$, while in some studies the affectivity of heparin was limited [17, 28-30]. Attenuation of metastasis was repeatedly observed in most of the studies despite a wide range of heparin dosages applied (Table 1). In most studies, the amount of heparin applied exceeded the therapeutic dose used in humans. Recently, the efficacy of heparin to inhibit metastasis was also documented at clinically relevant concentrations [26, 31]. In studies with a limited effect of heparin on metastasis [28], the applied heparin dosage was comparable to studies where attenuation of metastasis was detected (e.g. [25]. However, the limited response to heparin treatment was likely due to differences in time and/or route of heparin application, different amount of heparin applied and possible variation in heparin preparations [17, 28, 29, Niers, $2009 \# 2178]$. Clinically used heparin preparations are adjusted according to their anticoagulant acitivity. Accordingly, different heparin formulations are not necessarily identical in "other" biological activities responsible for the antimetastatic effect of heparin.

\section{Potential mechanisms for heparin affects on metastasis}

Hematogenous metastasis consist of a multistep process in which tumor cells enter the blood circulation, evade immune responses, adhere to the endothelium of distant organs, extravasate and colonize the tissue $[32,33]$. The common observation that a single injection of heparin, at the time when tumor cells are still in circulation, attenuates metastasis indicates that inhibition of cellular events during the hematogenous phase profoundly affect this process. This conclusion is further supported by the fact, that the half-life of heparin in blood circulation is relatively short and last for four to six hours $[14,34]$. Thus it is unlikely that heparin exerts its 
antimetastatic activity through inhibition of angiogenesis that would require a prolonged heparin treatment. Therefore, the antimetastatic activities of heparins were analyzed for their potential to: affect anticoagulation; inhibit heparanase and to block P- and L-selectin in particular.

\section{Anticoagulant activity and metastasis}

Unfractionated heparin and LMWH has been in clinical use for decades as an effective inhibitor of fluid phase coagulation by enhancing antithrombin inactivation of factors IIa and Xa. Intravenous injection of tumor cells leads to tumor cell emboli formation resulting in the tumor cell entrapment in the pulmonary vasculature [34-36]. Tumor cell associated activation of the coagulation cascade, often expressed by tumor cells, results in a rapid fibrin deposition detected both by intravascular tumor cells and in the metastatic lesions [36, 37]. Some experimental studies have demonstrated that anticoagulation using antithrombin inhibitor hirudin attenuated metastasis $[36,38]$. However, the dose of hirudin used led to an excessive anticoagulation affect that is not compatible with the clinical use. Conversely, a continuous treatment with an oral thrombin inhibitor led to an accelerated pulmonary metastasis [39]. Another anti-metastatic property of heparin, with respect to anticoagulation, is related to the capacity of heparin to release tissue factor pathway inhibitor (TFPI) from vascular endothelium thereby contributing to the antiangiogenic activity of the TF inhibitor [40-42]. The use of non-anticoagulant heparin derivatives in a number of animal models resulted in attenuation of metastasis, further demonstrating that the antimetastatic activity of heparins is independent of anticoagulation [14, 16, 17, 28, 43, 44]. The pentasaccharide fondaparinux, an excellent anticoagulant that potentiates antithrombin III, had no affect on metastasis at clinically tolerable levels [26, 31].

\section{Heparanase activity}


Tumor cell invasion is a critical step in the metastatic cascade. The invasiveness of tumor cells is associated with the capacity to degrade extracellular matrix components by producing hydrolytic enzymes such as matrix metalloproteinases or heparanase. Elevated levels of heparanase were associated with cancer progression and poor prognosis in various carcinomas of colon, liver, breast, bladder and also multiple myeloma [45]. Heparanase activity correlated with the metastatic potential of B16 mouse melanoma and Eb lymphoma cells [46, 47]. Heparin treatment inhibited heparanase activity and led to attenuation of metastasis $[47,48]$. In a myeloma cell model, enhanced expression of heparanase was shown to induce metastasis [49]. Heparanase expression in myeloma was associated with an enhanced shedding of syndecan-1 and correlated with poor prognosis $[50,51]$. Silencing of the heparanase gene led to marked reduction of heparanase enzymatic activity in B16 melanomas that resulted in reduced lung colonization [52]. Heparin derivatives characterized by their ability to inhibit heparanase were evaluated for their anti-metastatic activity in a number of animal models [11, 12, 22]. Since the antimetastatic activity of heparins may be caused by other biological activities, like inhibition cell-cell interaction mediated by P- and L-selectin, heparins were tested for both activities in parallel [14]. P-selectin specific heparin derivatives reduced metastasis of tumor cells regardless of heparanase expression. Heparin derivatives with specific heparanase inhibitory activity reduced the metastatic capacity of tumor cells (e.g. B16 melanoma cells) expressing this enzyme, while showing no affect with tumors without heparanase expression (MC-38 carcinoma cells). These results indicate that inhibition of selectins by heparin probably precedes the heparanase inhibitory activity as observed in the experimental metastasis model.

\section{Selectin as mediators of metastasis}


During hematogenous metastasis tumor cells in a blood circulation has to survive and adhere to the vasculature in the target organs. Enhanced platelets-tumor cell emboli formation correlated with metastatic progression [53-55]. Tumor cells covered with platelet aggregates were shown to evade immune responses in the blood circulation [56]. Thus, cell-cell interactions of tumor cell within the vascular environment are critical for metastatic progression. Selectins represent the major group of cell adhesion molecules that were linked to hematogenous metastasis. Selectins are vascular cell adhesion molecules that mediate the initial steps of leukocytes and platelets interactions with the endothelial cells under normal physiological condition [57]. While activation of platelets and endothelial cells lead to a rapid cell surface expression of P-selectin, virtually all populations of leukocytes constitutively express L-selectin. E-selectin expression on the cell surface of endothelial cell is induced by a prolonged activation. In addition to their physiological function, selectin were shown to contribute to metastasis by mediation of cell interaction among tumor cells, platelets, leukocytes and endothelial cells $[23,34,37,58-60]$. The absence of P-selectin led to attenuation of experimental metastasis in several animal models [23, 58, 59]. A marked reduction of platelet-tumor cell thrombi formation in P-selecitn deficient mice was found to be responsible for attenuation of metastasis [34, 58]. An experimental elimination of circulating platelets resulted in reduced metastasis [55], further supporting the role of platelets in this process. Collectively, these observations strongly indicate the pivotal role of P-selectin in facilitation of metastasis through mediation of platelet-tumor cell interactions. In addition, endothelial expression of P-selectin was also reported to enhance metastasis [23]. The bone marrow rescue of lethally irradiated P-selectin deficient mice with the wild type bone marrow led to a marked reduction of metastasis. This observation indicates that early endothelial activation, thereby $\mathrm{P}$-selectin expression on vasculature, contributes to metastasis in these chimeric mice where P-selectin is present on platelets only. E-selectin expression has been also studied for its potential to mediate metastasis. Transgenic overexpression of E-selectin in 
the liver increased metastasis to this tissue, indicating the involvement of E-selectin in liver metastasis [60]. In the absence of L-selectin significant attenuation of metastasis was observed in two different mouse models, thus actively implicating leukocytes in facilitation of metastasis [59]. Even a transient inhibition of L-selectin during the intravascular phase of tumor cells led to attenuation of metastasis to the comparable levels as observed in L-selectin deficient mice [37]. Further characterization of leukocytes suggested that myeloid-derived leukocytes through L-selectin mediated interactions mediate the initial steps of metastasis.

Selectins bind to specific glycan structures, which are presented on the cell surfaces of many tumor cells. Virtually all carcinomas express selectin ligands due to an abundant expression of mucins. Carcinoma mucins are carriers of O-glycan structures, including the expression of sialyl Lewis $x\left(\operatorname{sLe}^{\mathrm{x}}\right)$ that serves as the core component of a selectin ligand [61]. The positive correlation between $\mathrm{sLe}^{\mathrm{x}}$ expression and poor prognosis was observed in gastric, colon, lung, prostate and breast cancers [62-66]. The presence of carcinoma cells, carrying selectin ligands, in the blood circulation together with the presence vascular selectins makes them the potential mediators of cell interactions leading to metastasis.

\section{Heparin reduces metastasis through inhibition of selectins}

Heparin has a variety of biological activities, including the capacity to effectively inhibit Pand L-selectins despite no similarity to natural selectin ligands [13, 67]. The hypothesis that selectins mediate metastasis was explored by a number of laboratories, and the recent evidence confirmed the contribution of P-and L-selectin to metastasis [23, 34, 37]. To address the heparin activity during metastasis, P- and/or L-selectin deficient mice were injected with unfractionated heparin shortly before intravascular injection of either carcinoma or melanoma cells $[23,34,37,59]$. A single bolus injection of heparin attenuated metastasis in wild type 
mice to a similar level as observed in P-selectin deficient mice [23, 34]. Furthermore, single heparin injection in P-selectin deficient mice had no further effect on metastasis [34]. Interestingly, single dose of heparin prior to tumor cell injection further attenuated metastasis in L-selectin deficient mice, indicating that L-selectin involvement in this process is subsequent to P-selectin involvement [59]. This hypothesis was confirmed in another study, where L-selectin mediated recruitment to metastasis cells was observed 9 to12 hours after tumor cell injection [37]. When heparin was applied six hours after tumor cell injection further attenuation of metastasis was observed in P-selectin deficient mice. Conversely, the application of heparin six hours after tumor cell injections had no further effect on metastasis in L-selectin deficient mice [37]. When heparin was applied either shortly before or six hours after tumor cell injection no further effect on metastasis in P-and L-selectin double deficient mice was observed $[59,68]$. Interestingly, repeated injection of high doses of unfractionated heparin led to a prolonged survival of mice, indicating that heparin at such doses might have further antimetastatic activities to selectin inhibition [68]. Finally, extensive characterization of modified non-anticoagulant heparins led to identification of a particular heparin derivative (58\% $\mathrm{N}$-acetylated heparin), that contains excellent P-selectin inhibitory activity while preserving minimal heparanase inhibitory activity and reduced growth factor binding activity [14]. This heparin derivative reduced metastasis of mouse colon carcinoma and melanoma cells. Collectively, these findings strongly suggest that heparin inhibits metastasis by interference with P-and L-selectin mediated cell-cell interactions. While the contribution of Pselectin to metastasis is partially characterized, the consequence of L-selectin involvement, thereby leukocytes, remains to be further analyzed.

\section{Heparin attenuates metastasis. Published evidence versus a mechanism of action}


Hematogenous metastasis is directly or indirectly responsible for most cancer-related deaths. A summary of experimental evidence on heparin treatment of various cancer cells using a broad range of heparin doses as well as different heparin preparations and derivatives is presented in Table 1. Attenuation of metastasis has been observed when: 1) heparin was applied around the time of intravenous tumor cell injection; 2) the amount of heparin applied was at least at the clinically used concentrations. Only in two studies had heparin treatment no affect on metastasis when applied either one hour after tumor cell injection [29] or one hour before injection [17]. In most of the studies, heparin doses were several times higher than clinically used doses in humans. Considering the higher sensitivity of human P-selectin to heparin inhibition when compared to mouse P-selectin (about 10 fold difference), these findings suggest even better responses to be expected in humans, assuming that P-selectin is one of the primary targets during metastasis [69]. The affectivity of non-anticoagulant heparins to attenuate metastasis clearly separates the anticoagulant activity of heparin from its antimetastatic activity. Considering the transient presence of heparin in blood circulation that usually last for several hours [34], the possible biological activity of heparin on angiogenesis, tumor cell growth and invasiveness mediated by heparanase are rather limited. The accumulated evidence on the anti-metastatic activity of heparin over the large number of studies is compatible with the described role of P- and L-selectin mediated interactions during hematogenous metastasis. Further characterizations of heparins will provide additional insights into the precise mechanism of heparin action during metastasis. However, it might well be that "the sum" of biological activities defined by the very nature of heparin molecules will be the right treatment of cancer progression affecting not only selectins or heparanase, but also a number of other mechanisms potentially critical in a different cancers. Finally, the available evidence from clinical trials [4] strongly supports the future evaluation of heparin as a potential anti-metastatic treatment. 


\section{Acknowledgements}

This work was supported by the grant from Swiss National Science Foundation \#3100A0116295 to L.B.

\section{References}

1. Rickles FR, Falanga A. Molecular basis for the relationship between thrombosis and cancer. Thromb Res 2001;102:V215-V224.

2. Zacharski LR, Ornstein DL. Heparin and cancer. Thromb Haemost 1998;80:10-23.

3. Falanga A, Marchetti M. Heparin in tumor progression and metastatic dissemination. Semin Thromb Hemost 2007;33:688-694.

4. Zacharski LR, Lee AY. Heparin as an anticancer therapeutic. Expert Opin Investig Drugs 2008;17:1029-1037.

5. Kuderer NM, Khorana AA, Lyman GH, Francis CW. A meta-analysis and systematic review of the efficacy and safety of anticoagulants as cancer treatment: impact on survival and bleeding complications. Cancer 2007;110:1149-1161.

6. Tagalakis V, Blostein M, Robinson-Cohen C, Kahn SR. The effect of anticoagulants on cancer risk and survival: systematic review. Cancer Treat Rev 2007;33:358-368.

7. Niers TM, Klerk CP, DiNisio M, et al. Mechanisms of heparin induced anti-cancer activity in experimental cancer models. Crit Rev Oncol Hematol 2007;61:195-207.

8. Smorenburg SM, Van Noorden CJ. The complex effects of heparins on cancer progression and metastasis in experimental studies. Pharmacol Rev 2001;53:93-105.

9. Lever R, Page CP. Novel drug development opportunities for heparin. Nat Rev Drug Discov $2002 ; 1: 140-148$.

10. Esko JD, Lindahl U. Molecular diversity of heparan sulfate. J Clin Invest 2001;108:169-173. 
11. Miao HQ, Elkin M, Aingorn E, et al. Inhibition of heparanase activity and tumor metastasis by laminarin sulfate and synthetic phosphorothioate oligodeoxynucleotides. Int J Cancer 1999;83:424-431.

12. Parish CR, Freeman C, Brown KJ, Francis DJ, Cowden WB. Identification of sulfated oligosaccharide-based inhibitors of tumor growth and metastasis using novel in vitro assays for angiogenesis and heparanase activity. Cancer Res 1999;59:3433-3441.

13. Koenig A, Norgard-Sumnicht K, Linhardt R, Varki A. Differential interactions of heparin and heparan sulfate glycosaminoglycans with the selectins. Implications for the use of unfractionated and low molecular weight heparins as therapeutic agents. J Clin Invest 1998;101:877-889.

14. Hostettler N, Naggi A, Torri G, et al. P-selectin- and heparanase-dependent antimetastatic activity of non-anticoagulant heparins. FASEB J 2007;21:3562-3572.

15. Naggi A, Casu B, Perez M, et al. Modulation of the heparanase-inhibiting activity of heparin through selective desulfation, graded N-acetylation, and glycol splitting. J Biol Chem 2005;280:12103-12113.

16. Kragh M, Binderup L, Vig Hjarnaa PJ, et al. Non-anti-coagulant heparin inhibits metastasis but not primary tumor growth. Oncol Rep 2005;14:99-104.

17. Yoshitomi $\mathrm{Y}$, Nakanishi $\mathrm{H}$, Kusano $\mathrm{Y}$, et al. Inhibition of experimental lung metastases of Lewis lung carcinoma cells by chemically modified heparin with reduced anticoagulant activity. Cancer Lett 2004;207:165-174.

18. Mousa SA, Linhardt R, Francis JL, Amirkhosravi A. Anti-metastatic effect of a nonanticoagulant low-molecular-weight heparin versus the standard low-molecular-weight heparin, enoxaparin. Thromb Haemost 2006;96:816-821.

19. Park K, Ki Lee S, Hyun Son D, et al. The attenuation of experimental lung metastasis by a bile acid acylated-heparin derivative. Biomaterials 2007;28:2667-2676.

20. Lee AE, Rogers LA, Longcroft JM, Jeffery RE. Reduction of metastasis in a murine mammary tumour model by heparin and polyinosinic-polycytidylic acid. Clin Exp Metastasis $1990 ; 8: 165-171$ 
21. Sciumbata T, Caretto P, Pirovano P, et al. Treatment with modified heparins inhibits experimental metastasis formation and leads, in some animals, to long-term survival. Invasion Metastasis 1996;16:132-143.

22. Vlodavsky I, Mohsen M, Lider O, et al. Inhibition of tumor metastasis by heparanase inhibiting species of heparin. Invasion Metastasis 1994;14:290-302.

23. Ludwig RJ, Boehme B, Podda M, et al. Endothelial P-selectin as a target of heparin action in experimental melanoma lung metastasis. Cancer Res 2004;64:2743-2750.

24. Bereczky B, Gilly R, Raso E, et al. Selective antimetastatic effect of heparins in preclinical human melanoma models is based on inhibition of migration and microvascular arrest. Clin Exp Metastasis 2005;22:69-76.

25. Amirkhosravi A, Mousa SA, Amaya M, Francis JL. Antimetastatic effect of tinzaparin, a lowmolecular-weight heparin. J Thromb Haemost 2003;1:1972-1976.

26. Stevenson JL, Choi SH, Varki A. Differential metastasis inhibition by clinically relevant levels of heparins--correlation with selectin inhibition, not antithrombotic activity. Clin Cancer Res 2005;11:7003-7011.

27. Lee AE, Rogers LA, Jeffery RE, Longcroft JM. Comparison of metastatic cell lines derived from a murine mammary tumour, and reduction of metastasis by heparin. Clin Exp Metastasis $1988 ; 6: 463-471$

28. Lapierre F, Holme K, Lam L, et al. Chemical modifications of heparin that diminish its anticoagulant but preserve its heparanase-inhibitory, angiostatic, anti-tumor and antimetastatic properties. Glycobiology 1996;6:355-366.

29. Szende B, Paku S, Racz G, Kopper L. Effect of Fraxiparine and heparin on experimental tumor metastasis in mice. Anticancer Res 2005;25:2869-2872.

30. Niers TM, Bruggemann LW, Klerk CP, et al. Differential effects of anticoagulants on tumor development of mouse cancer cell lines B16, K1735 and CT26 in lung. Clin Exp Metastasis 2009;26:171-178. 
31. Ludwig RJ, Alban S, Bistrian R, et al. The ability of different forms of heparins to suppress Pselectin function in vitro correlates to their inhibitory capacity on bloodborne metastasis in vivo. Thromb Haemost 2006;95:535-540.

32. Steeg PS. Tumor metastasis: mechanistic insights and clinical challenges. Nat Med 2006;12:895-904.

33. Gupta GP, Massague J. Cancer metastasis: building a framework. Cell 2006;127:679-695.

34. Borsig L, Wong R, Feramisco J, et al. Heparin and cancer revisited: mechanistic connections involving platelets, P-selectin, carcinoma mucins, and tumor metastasis. Proc Natl Acad Sci U S A 2001;98:3352-3357.

35. Varki NM, Varki A. Heparin Inhibition of Selectin-Mediated Interactions during the Hematogenous Phase of Carcinoma Metastasis: Rationale for Clinical Studies in Humans. Semin Thromb Hemost 2002;28:53-66.

36. Im JH, Fu W, Wang H, et al. Coagulation facilitates tumor cell spreading in the pulmonary vasculature during early metastatic colony formation. Cancer Res 2004;64:8613-8619.

37. Laubli H, Stevenson JL, Varki A, Varki NM, Borsig L. L-selectin facilitation of metastasis involves temporal induction of fut7-dependent ligands at sites of tumor cell arrest. Cancer Res 2006;66:1536-1542.

38. Hu L, Lee M, Campbell W, Perez-Soler R, Karpatkin S. Role of endogenous thrombin in tumor implantation, seeding, and spontaneous metastasis. Blood 2004;104:2746-2751.

39. Niers TM, Bruggemann LW, GL VANS, et al. Long-term thrombin inhibition promotes cancer cell extravasation in a mouse model of experimental metastasis. J Thromb Haemost 2009;7:1595-1597.

40. Vlodavsky I, Ilan N, Nadir Y, et al. Heparanase, heparin and the coagulation system in cancer progression. Thromb Res 2007;120 Suppl 2:S112-120.

41. Amirkhosravi A, Meyer T, Amaya M, et al. The role of tissue factor pathway inhibitor in tumor growth and metastasis. Semin Thromb Hemost 2007;33:643-652.

42. Mousa SA, Petersen LJ. Anti-cancer properties of low-molecular-weight heparin: preclinical evidence. Thromb Haemost 2009;102:258-267. 
43. Vlodavsky I, Eldor A, Haimovitz-Friedman A, et al. Expression of heparanase by platelets and circulating cells of the immune system: possible involvement in diapedesis and extravasation. Invasion Metastasis 1992;12:112-127.

44. Ono K, Ishihara M, Ishikawa K, et al. Periodate-treated, non-anticoagulant heparin-carrying polystyrene (NAC-HCPS) affects angiogenesis and inhibits subcutaneous induced tumour growth and metastasis to the lung. Br J Cancer 2002;86:1803-1812.

45. Ilan N, Elkin M, Vlodavsky I. Regulation, function and clinical significance of heparanase in cancer metastasis and angiogenesis. Int J Biochem Cell Biol 2006;38:2018-2039.

46. Goldshmidt O, Zcharia E, Abramovitch R, et al. Cell surface expression and secretion of heparanase markedly promote tumor angiogenesis and metastasis. Proc Natl Acad Sci U S A 2002;99:10031-10036.

47. Irimura T, Nakajima M, Nicolson GL. Chemically modified heparins as inhibitors of heparan sulfate specific endo-beta-glucuronidase (heparanase) of metastatic melanoma cells. Biochemistry 1986;25:5322-5328.

48. Bar-Ner M, Eldor A, Wasserman L, et al. Inhibition of heparanase-mediated degradation of extracellular matrix heparan sulfate by non-anticoagulant heparin species. Blood 1987;70:551557.

49. Yang Y, Macleod V, Bendre M, et al. Heparanase promotes the spontaneous metastasis of myeloma cells to bone. Blood 2005;105:1303-1309.

50. Yang Y, Macleod V, Miao HQ, et al. Heparanase Enhances Syndecan-1 Shedding: A NOVEL MECHANISM FOR STIMULATION OF TUMOR GROWTH AND METASTASIS. J Biol Chem 2007;282:13326-13333.

51. Sanderson RD, Yang Y. Syndecan-1: a dynamic regulator of the myeloma microenvironment. Clin Exp Metastasis 2008;25:149-159.

52. Edovitsky E, Elkin M, Zcharia E, Peretz T, Vlodavsky I. Heparanase gene silencing, tumor invasiveness, angiogenesis, and metastasis. J Natl Cancer Inst 2004;96:1219-1230.

53. Tanaka NG, Tohgo A, Ogawa H. Platelet-aggregating activities of metastasizing tumor cells. V. In situ roles of platelets in hematogenous metastases. Invasion Met 1986;6:209-224. 
54. Honn KV, Tang DG, Crissman JD. Platelets and cancer metastasis: a causal relationship? Cancer Metastasis Rev 1992;11:325-351.

55. Karpatkin S, Pearlstein E, Ambrogio C, Coller BS. Role of adhesive proteins in platelet tumor interaction in vitro and metastasis formation in vivo. J Clin Invest 1988;81:1012-1019.

56. Nieswandt B, Hafner M, Echtenacher B, Mannel DN. Lysis of tumor cells by natural killer cells in mice is impeded by platelets. Cancer Res 1999;59:1295-1300.

57. Kansas GS. Selectins and their ligands: current concepts and controversies. Blood 1996;88:3259-3287.

58. Kim YJ, Borsig L, Varki NM, Varki A. P-selectin deficiency attenuates tumor growth and metastasis. Proc Natl Acad Sci U S A 1998;95:9325-9330.

59. Borsig L, Wong R, Hynes RO, Varki NM, Varki A. Synergistic effects of L- and P-selectin in facilitating tumor metastasis can involve non-mucin ligands and implicate leukocytes as enhancers of metastasis. Proc Natl Acad Sci U S A 2002;99:2193-2198.

60. Biancone L, Araki M, Araki K, Vassalli P, Stamenkovic I. Redirection of tumor metastasis by expression of E-selectin in vivo. J Exp Med 1996;183:581-587.

61. Kannagi R. Carbohydrate-mediated cell adhesion involved in hematogenous metastasis of cancer. Glycoconj J 1997;14:577-584.

62. Tatsumi M, Watanabe A, Sawada H, et al. Immunohistochemical expression of the sialyl Lewis $\mathrm{x}$ antigen on gastric cancer cells correlates with the presence of liver metastasis. Clin Exp Metastasis 1998;16:743-750.

63. Nakamori S, Kameyama M, Imaoka S, et al. Involvement of carbohydrate antigen sialyl Lewis(x) in colorectal cancer metastasis. Dis Colon Rectum 1997;40:420-431.

64. Ogawa JI, Inoue H, Koide S. alpha-2,3-Sialyltransferase type $3 \mathrm{~N}$ and alpha-1,3fucosyltransferase type VII are related to sialyl Lewis(x) synthesis and patient survival from lung carcinoma. Cancer 1997;79:1678-1685.

65. Jorgensen T, Berner A, Kaalhus O, et al. Up-regulation of the oligosaccharide sialyl LewisX: a new prognostic parameter in metastatic prostate cancer. Cancer Res 1995;55:1817-1819. 
66. Idikio HA. Sialyl-Lewis-X, Gleason grade and stage in non-metastatic human prostate cancer. Glycoconj J 1997;14:875-877.

67. Nelson RM, Cecconi O, Roberts WG, et al. Heparin oligosaccharides bind L- and P-selectin and inhibit acute inflammation. Blood 1993;82:3253-3258.

68. Stevenson JL, Varki A, Borsig L. Heparin attenuates metastasis mainly due to inhibition of Pand L-selectin, but non-anticoagulant heparins can have additional effects. Thromb Res 2007;120 Suppl 2:S107-111.

69. Borsig L. Selectins facilitate carcinoma metastasis and heparin can prevent them. News Physiol Sci 2004;19:16-21.

70. Poggi A, Rossi C, Casella N, et al. Inhibition of B16-BL6 melanoma lung colonies by semisynthetic sulfaminoheparosan sulfates from E. coli K5 polysaccharide. Semin Thromb Hemost 2002;28:383-392.

71. Mellor P, Harvey JR, Murphy KJ, et al. Modulatory effects of heparin and short-length oligosaccharides of heparin on the metastasis and growth of LMD MDA-MB 231 breast cancer cells in vivo. Br J Cancer 2007;97:761-768.

72. Harvey JR, Mellor P, Eldaly H, et al. Inhibition of CXCR4-mediated breast cancer metastasis: a potential role for heparinoids? Clin Cancer Res 2007;13:1562-1570.

73. Lee DY, Park K, Kim SK, et al. Antimetastatic effect of an orally active heparin derivative on experimentally induced metastasis. Clin Cancer Res 2008;14:2841-2849.

74. Yee CK, Butcher M, Zeadin M, Weitz JI, Shaughnessy SG. Inhibition of osteolytic bone metastasis by unfractionated heparin. Clin Exp Metastasis 2008;25:903-911.

75. Zhang C, Liu Y, Gao Y, et al. Modified heparins inhibit integrin alpha(IIb)beta(3) mediated adhesion of melanoma cells to platelets in vitro and in vivo. Int J Cancer 2009;125:2058-2065. 
Table 1

Effect of heparins on experimentally induced lung metastasis after the intravenous injection of cancer cells

\begin{tabular}{|c|c|c|c|c|}
\hline Tumor type & Heparin dose $^{a}$ & Doses schedule $^{b}$ & Effect on Metastasis & Reference \\
\hline M mammary carcinoma & UFH $40 \mathrm{IU} /$ mouse & $-24 \mathrm{~h}$ and $-1 \mathrm{~h}$ i.p. & Decrease & Lee et al. [27] \\
\hline M mammary carcinoma & UFH $40 \mathrm{IU} / \mathrm{kg}$ & $-24 \mathrm{~h}$ and - 1 h i.p. & Decrease & Lee et al. [20] \\
\hline \multirow[t]{4}{*}{ M melanoma } & UFH 0.4 mg/mouse & -20 min i.v. & Decrease & Vlodavsky et al. [22] \\
\hline & & - 1 day i.v. & No effect & \\
\hline & LMWH 0.4 mg/mouse & -20 min i.v. & Decrease & \\
\hline & & - 1 day i.v. & No effect & \\
\hline M melanoma & UFH modified $10 \mathrm{mg} / \mathrm{kg}$ & - 10 min \& twice a week i.v. & Decrease & Sciumbata et al. [21] \\
\hline \multirow[t]{2}{*}{ M melanoma } & UFH modified $50 \mathrm{mg} / \mathrm{kg}$ & - $1 \mathrm{~h}$ \& once daily for 3 days s.q. & Decrease & Lapierre et al. [28] \\
\hline & UFH modified $10 \mathrm{mg} / \mathrm{kg}$ & - 1 h \& once daily for 3 days s.q. & No effect & \\
\hline M melanoma & LMWH $100 \mu \mathrm{g} / \mathrm{mouse}$ & -20 min i.v. & Decrease & Miao et al. [11] \\
\hline R mammary carcinoma & LMWH $3.6 \mathrm{mg} / \mathrm{rat}$ & - 20 min i.p. & Decrease & \\
\hline H colon carcinoma & UFH $100 \mathrm{IU} /$ mouse & -30 min i.v. & Decrease & Borsig et al. [34] \\
\hline M colon carcinoma & UFH $100 \mathrm{IU} / \mathrm{mouse}$ & -30 min i.v. & Decrease & Borsig et al. [59] \\
\hline \multirow[t]{2}{*}{ M melanoma } & UFH and UFH modified $0.2-0.5 \mathrm{mg} / \mathrm{mouse}$ & Coinjected i.v. & Decrease & Poggi et al. [70] \\
\hline & UFH and UFH modified 0.1-0.5 mg/mouse & $-1 \mathrm{~h}$ i.v. & Decrease & \\
\hline M melanoma & LAC H or LMWH 1.0 mg/mouse & once daily for 7 days i.v. & Decrease & Ono et al. [44] \\
\hline M lung carcinoma & LAC H or LMWH 1.0 mg/mouse & once daily for 7 days i.v. & Decrease & \\
\hline M melanoma & LMWH 10 mg/kg & - 4 h s.q. & Decrease & Amirkhosravi et al. [25] \\
\hline \multirow[t]{2}{*}{ M melanoma } & UFH 12.5 or $60 \mathrm{IU} / \mathrm{mouse}$ & - 30 min route not specified & Decrease & Ludwig et al. [23] \\
\hline & UFH $60 \mathrm{IU} /$ mouse & $+24 \mathrm{~h}$ and then every second day & No effect & \\
\hline \multirow[t]{2}{*}{ M lung carcinoma } & LAC H 0.5-2.0 mg/mouse & -10 min i.v. & Decrease & Yoshitomi et al [17] \\
\hline & LAC H $1 \mathrm{mg} / \mathrm{mouse}$ & -1 h s.q. & No effect & \\
\hline M melanoma & LAC H $1 \mathrm{mg} / \mathrm{mouse}$ & -10 min i.v. & Decrease & \\
\hline M colon carcinoma & LAC H $1 \mathrm{mg} / \mathrm{mouse}$ & - 10 min i.v. & Decrease & \\
\hline M osteosarcoma & LAC H $1 \mathrm{mg} / \mathrm{mouse}$ & -10 min i.v. & Decrease & \\
\hline \multirow[t]{2}{*}{ M colon carcinoma } & UFH 6.6 IU/mouse & - 30 min s.q. & Decrease & Stevenson et al. [26] \\
\hline & LMWH 7.3 IU/mouse & -30 min s.q. & Decrease & \\
\hline M melanoma & UFH 6.6 IU/mouse & - 30 min s.q. & Decrease & \\
\hline
\end{tabular}




\begin{tabular}{|c|c|c|c|c|}
\hline & LMWH 7.3 IU/mouse & -30 min s.q. & Decrease & \\
\hline M melanoma & NAC H 50 mg/kg & - 4 h s.q. & Decrease & Kragh et al. [16] \\
\hline H melanoma & UFH and LMWH $200 \mathrm{IU} / \mathrm{kg}$ & - 1 day $\&$ once daily for 3 days i.p. & Decrease & Bereczky et al. [24] \\
\hline \multirow[t]{3}{*}{ M lung carcinoma } & UFH $100 \mathrm{IU} / \mathrm{mouse}$ & +1 h s.q. & No effect & Szende et al. [29] \\
\hline & LMWH 38 IU/mouse & +1 h s.q. & No effect & \\
\hline & LMWH 57 IU/mouse & +1 h s.q. & Decrease & \\
\hline M colon carcinoma & UFH $100 \mathrm{IU} /$ mouse & $+6 \mathrm{~h}$ and $+12 \mathrm{~h}$ i.v. & Decrease & Laubli et al. [37] \\
\hline M melanoma & LMWH and NAC LMWH $200 \mu \mathrm{g} /$ mouse & - 4 h s.q. & Decrease & Mousa et al. [18] \\
\hline \multirow[t]{2}{*}{ M melanoma } & UFH 10-60 IU/mouse & $-30 \min$ i.v. & Decrease & Ludwig et al. [31] \\
\hline & LMWH $60 \mathrm{IU} / \mathrm{mouse}$ & -30 min i.v. & Decrease & \\
\hline \multirow[t]{2}{*}{ M melanoma } & UFH 0.5-5 mg/kg & -20 min i.v. & Decrease & Park et al. [19] \\
\hline & UFH modified $0.5-5 \mathrm{mg} / \mathrm{kg}$ & -20 min i.v. & Decrease & \\
\hline \multirow[t]{2}{*}{ M squamous cell carcinoma } & UFH 0.5-5 mg/kg & $-20 \min$ i.v. & Decrease & \\
\hline & UFH modified 0.5-5 mg/kg & -20 min i.v. & Decrease & \\
\hline $\mathrm{H}$ breast carcinoma & UFH $3.3 \mathrm{mg} / \mathrm{kg}$ & - 4 h \& twice daily s.q. & Decrease & Mellor et al. [71] \\
\hline \multirow[t]{2}{*}{ H breast carcinoma } & LMWH $175 \mathrm{IU} / \mathrm{kg}$ & - 4 h \& once daily s.q. & Decrease & Harvey et al. [72] \\
\hline & LMWH 90 IU/kg & - 4 h \& once daily for 4 days s.q. & Decrease & \\
\hline M colon carcinoma & UFH modified $150 \mu \mathrm{g} / \mathrm{mouse}$ & $-10 \min$ i.v. & Decrease & Hostettler et al. [14] \\
\hline \multirow[t]{2}{*}{ M melanoma } & UFH modified $150 \mu \mathrm{g} / \mathrm{mouse}$ & -10 min i.v. & Decrease & \\
\hline & UFH modified $300 \mu \mathrm{g} / \mathrm{mouse}$ & - 30 min s.q. & Decrease & \\
\hline \multirow[t]{2}{*}{ M melanoma } & LMWH modified 1-10 mg/kg & - 20 min \& once daily orally & Decrease & Lee et al. [73] \\
\hline & LMWH modified $1 \mathrm{mg} / \mathrm{kg}$ & - 20 min i.v. \& once daily orally & Decrease & \\
\hline H lung carcinoma & LMWH modified $10 \mathrm{mg} / \mathrm{kg}$ & - 20 min \& once daily orally & Decrease & \\
\hline M melanoma & UFH 15-25 USP/mouse & - 30 min s.q. & Decrease & Yee et al. [74] \\
\hline M melanoma & LMWH 600IU/kg & prior to tumor cell injection i.p. & No effect & Niers et al. [30] \\
\hline M melanoma & NAC LMWH 10mg/kg & - 10 min route not specified & Decrease & Niers et al. [39] \\
\hline M melanoma & UFH and UFH modified $5 \mathrm{mg} / \mathrm{kg}$ & - 30 min route not specified & Decrease & Zhang et al. [75] \\
\hline
\end{tabular}

${ }^{a}$ UFH modified is specifically desulfated; LAC - low anticoagulant, obtained by chemical modification of the heparin; NAC - non-anti-coagulant.

${ }^{\mathrm{b}}$ Timing of the heparin administration is given in reference to injection of tumor cells. A negative value refers to heparin injection prior to tumor cell administration. Route of heparin administration: i.v. = intravenous; s.q. = subcutaneous; i.p. = intraperitoneal.

$M=$ mouse, $H=$ human, $R=$ rat 